Egyptian

Orthodontic Journal

\title{
EVALUATION OF CRANIOFACIAL GROWTH CHANGES \\ IN SUBJECTS WITH CLASS II AND CLASS III MALOCCLUSIONS DURING THE CIRCUM-PUBERTAL PERIOD
}

\author{
Sara M. El-Kabbany ${ }^{1}$, Samir A. Ibrahim², Ahmed E. Salama ${ }^{3}$, \\ Sheldon Baumrind ${ }^{4}$
}

\section{ABSTRACT:}

The issue of craniofacial growth has become more relevant because of the increasing interest in optimizing treatment timing in dentofacial orthopedics. Objective: The purpose of this study was to evaluate craniofacial growth changes in skeletal Class II and Class III subjects in comparison with an age and sex matched control group with normal dentoskeletal pattern. Materials and Methods: The sample was randomly collected from the files of the American Association of Orthodontists Foundation Legacy Collection (AAOF). The final sample consisted of 170 subjects; 75 skeletal Class II subjects (33 females and 42 males), 15 skeletal Class III subjects (5 females and 10 males)

1- Assistant Lecturer of Orthodontics, Faculty of Dental Medicine (For Girls), Al-Azhar University; PhD Visiting Scholar ,Orthodontic Department, School of Dentistry, University of the Pacific, San Francisco, California, U.S.A.

2- Professor and Head of Orthodontic Department, Faculty of Dental Medicine (For Girls), Al-Azhar University.

3- Professor of Orthodontics, Faculty of Dental Medicine (For Girls), Al-Azhar University.

4- Professor of Orthodontics, Director of Craniofacial Research Instrumentation Lab, University of the Pacific School of Dentistry, San Francisco, CA, USA.

The current study was extracted from $\mathrm{PhD}$ thesis in Orthodontics, Orthodontic Department, Faculty of Dental Medicine (For Girls), Al-Azhar University, Cairo, Egypt. 
and 80 control subjects (38females and 42 males) with chronologic ages from 8 to 18 years old. The digital cephalometric radiographs were traced with replication using special software developed at the Craniofacial Research Instrumentation Laboratory. Cephalometric analysis of twenty skeletal and dental variables was performed. The stages in cervical vertebral maturation (CVMM) were recorded from cephalometric records of Class II subjects. Results: 1) Most dentofacial measures in Class II subjects were similar to control group, with the exception of significant mandibular retrusion, higher value of wits appraisal and $\mathcal{A N} B$ angle, distal molar relationship, greater skeletal convexity and deficiency in mandibular length. 2) Relative to controls, Class III subjects displayed smaller anterior cranial base length, similar cranial base angle, shorter maxilla, more prominent mandible, and increases in lower anterior facial height. 3) Most of the angular and linear measurements showed no significant sex difference in Class II group. In contrast, presence of a sexual dimorphism was evident in Class III group. Conclusion: 1. The skeletal and dental components of Class II and Class III malocclusion were evident early and didn't tend to self-correct with growth. 2. In Class II group, the adolescent growth spurt in mandibular length occurred at 12 to $13 y$ rs of age in females and 13 to $14 y$ rs of age in males. In 6oth sexes, the mandibular growth peak occurred between cervical vertebral stages three and four (CS3-CS4). 3. The peak of mandibular growth in Class III group showed a later onset, longer duration, and larger amount than controls. There was a significant increase in mandibular length in Class III subjects from about 11 in females and 14 in males through 16 years of age. 
Egyptian

Orthodontic Journal

\section{INTRODUCTION}

Evidence-based orthodontic practice requires research into treatment outcome of various modalities. To facilitate this, the influence of normal growth during a study period should be isolated from the data to distill the effect of treatment intervention. Class II and Class III growth research has been primarily cross-sectional in nature. Existing longitudinal studies have been limited in both number of subjects, number of time points studied, and the lack of age and gender matched Class I controls.

The studies on Class II skeletal patterns with a longitudinal design have showed variability in the findings. ${ }^{1-3,4,5}$ There were various problems associated with some of these studies. First, they were statistically unreliable as a result of insufficient sample size. Second, the samples were also mixed, with no distinction made regarding genders. Third, the samples were grouped according to chronological age or the dentition stages rather than skeletal age. Fourth, the common use of certain angular measurements considered to be reliable indicators of jaw position were later proved less reliable. ${ }^{6-8}$ Fifth, lack of control group in some of these studies.

Only a few major longitudinal studies have investigated craniofacial growth changes of untreated Class II subjects compared with untreated subjects with normal occlusion as a control group. . $^{911,12-15}$

On the other hand, most growth trend data on white people with untreated Class III malocclusions come from cross-sectional cephalometric studies. Such studies have revealed that Class III growth has significant differences from Class I growth. ${ }^{16-18,19,20}$

Longitudinal data on Class III subjects of European ancestry have become available only within the last decade. ${ }^{21,22,23}$ Such studies were limited in either sample size or observation interval, or lack of control group; this unfortunately restricts their applicability to Class III subjects meeting the same inclusion criteria. By reviewing the available literature, very few previous investigations were longitudinal in nature and analyzed enough set of skeletal Class II and Class III subjects to derive an estimate of craniofacial growth during the developmental ages in boys and girls 
separately. Consequently, the purpose of this investigation was to evaluate growth of skeletal Class II and Class III subjects longitudinally and to compare these with age and gender matched controls with normal dentoskeletal pattern.

\section{MATERIALS AND METHODS}

The Craniofacial Research Instrumentation Laboratory* (CRIL, Department of Orthodontics, University of the Pacific, Arthur A. Dugoni School of Dentistry, SanFrancisco, California, USA.)(Fig.1) has an access to an integrated collection of longitudinal lateral cephalograms and data from nine North American collections grouped together in the American Association of Orthodontists Foundation (AAOF) Legacy Collection $^{* * 24}$.

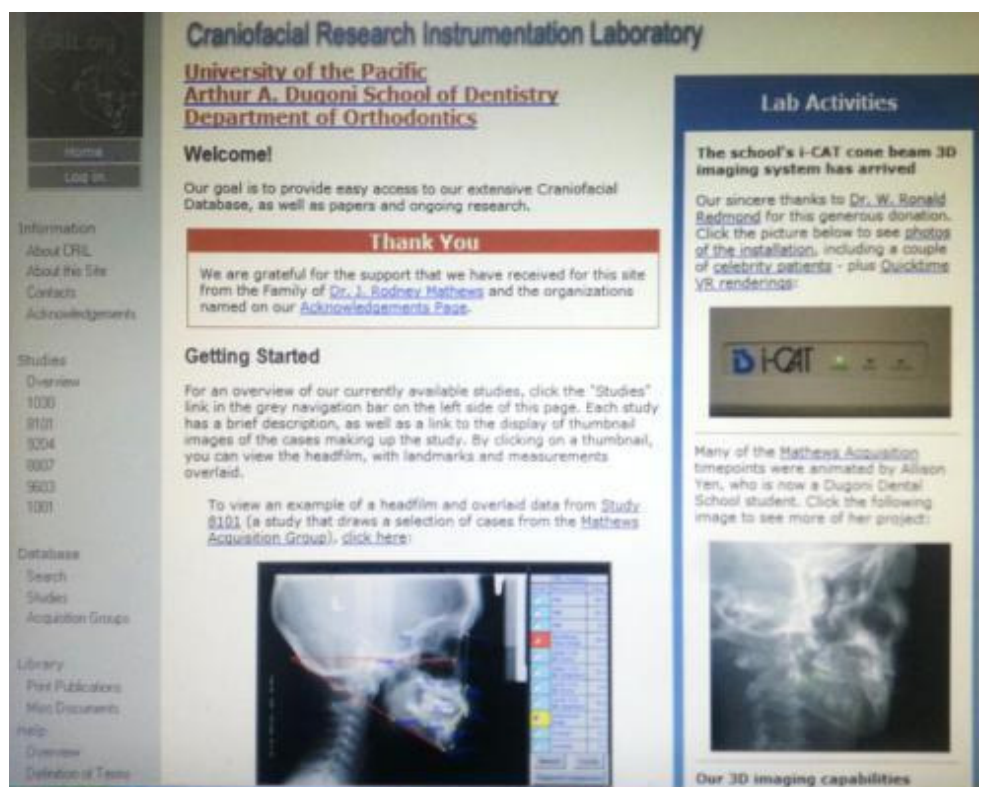

Fig. (1): The Craniofacial Research Instrumentation Lab (CRIL) (www.cril.org).

\footnotetext{
*Www.cril.org

**www.AAOFLegacyCollection.org
} 
This important project has a primary role of preserving irreplaceable longitudinal records of craniofacial development and represents an essential landmark in the development of open collaborative databases for orthodontic research and teaching (Fig.2).

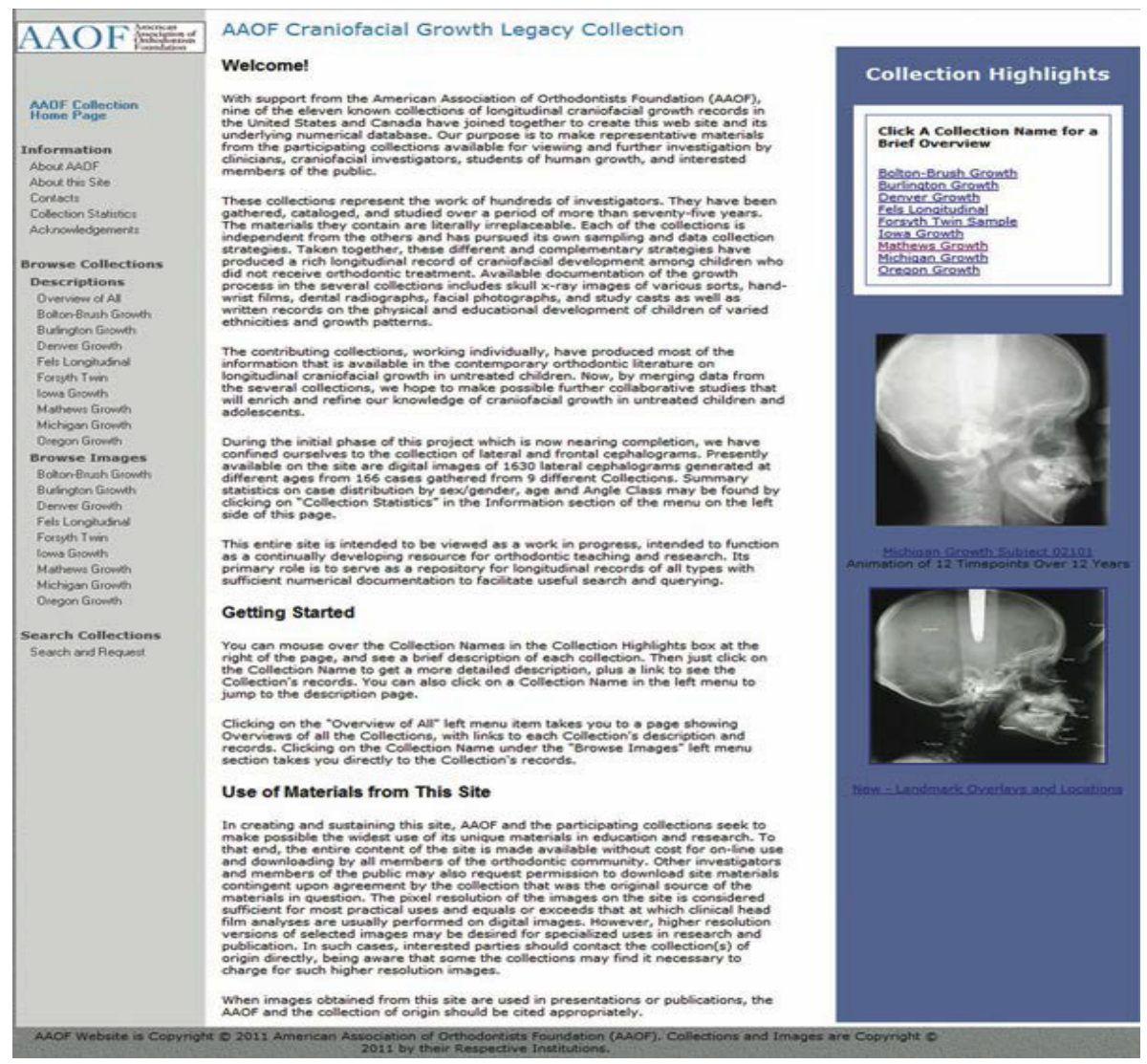

Fig. (2): The AAOF Legacy website home page

For this longitudinal retrospective study, Serial lateral cephalograms of subjects with Class II and Class III malocclusions were randomly sampled from the files of the American Association of Orthodontists Foundation Legacy Collection. They were matched for age and gender with control subjects with normal dentoskeletal pattern from the same source (Fig. 3, 4). 
Egyptian

Orthodontic Journal

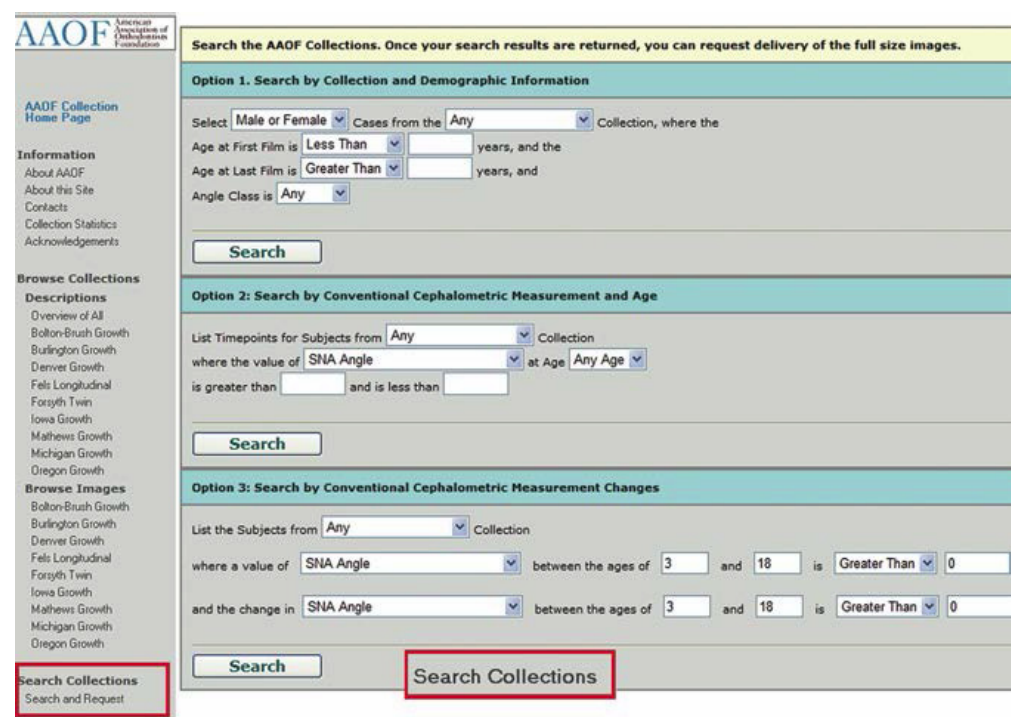

Fig. (3): Query form for searching the collections.

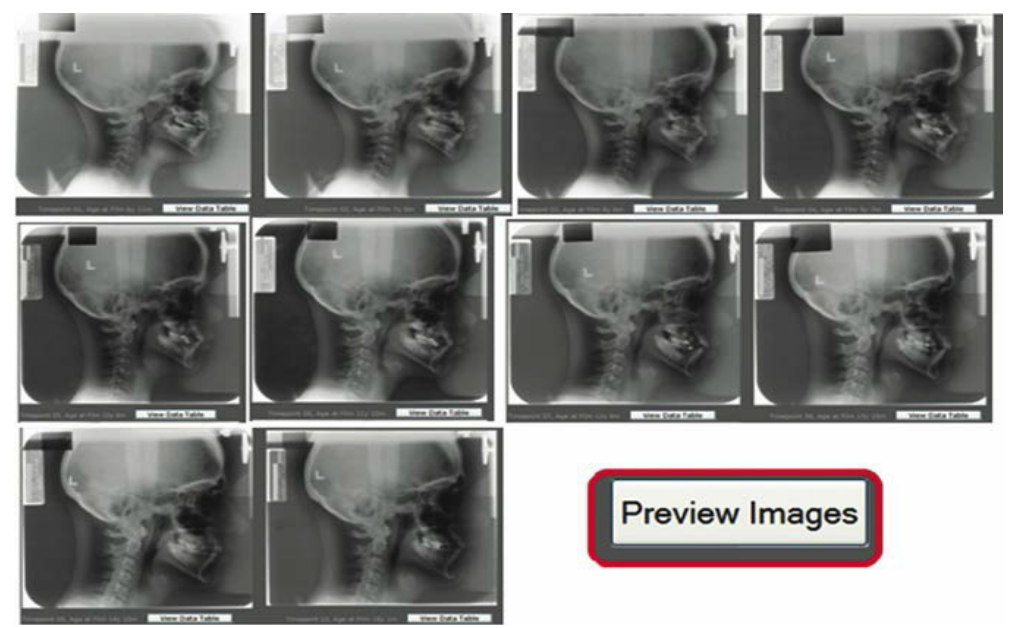

Fig. (4): Images for the lateral cephalograms at all available time points for a Case of Mathews collection.

The initial sample included 185 subjects with longitudinal lateral cephalometric series ranged between 5 and 10 films. The inclusion criteria in this study were; Lateral cephalograms of sufficient quality for landmark identification, Caucasian ancestry and chronologic ages from 8 to 18 years old. Exclusion criteria were any of the following: Previous 
orthodontic or orthopedic treatment, poor quality records, systematic diseases or craniofacial syndromes that could have affected general development, congenitally missing or extracted teeth and less than nine months between consecutive cephalometric films.

The sample was divided into three groups according to the sagittal skeletal pattern: Group I: Control Subjects with normal dentoskeletal pattern defined by the following signs: Class I molar relationship, normal overjet $(2-4 \mathrm{~mm})$, and (ANB angle between $1^{\circ}$ and $4.5^{\circ}$ ). Group II: Skeletal Class II Subjects defined by the following signs: Class II division 1 malocclusion (overjet greater than $5 \mathrm{~mm}$, full cusp Class II or end-to-end molar relationships), retrognathic mandible $\left(\mathrm{SNB}<75^{\circ}\right)$ and ANB angle more than $4.5^{\circ}$. Group III: Skeletal Class III Subjects defined by the following signs: full-cusp or half-cusp Class III molar relationship, anterior cross bite or an edge-to-edge incisal relationship, either or both a negative Wits appraisal greater than $-2.0 \mathrm{~mm}$ and an ANB angle less than $1^{\circ}$.

The final sample consisted of 170 subjects; 75 Class II subjects (33 females and 42 males), 15 Class III subjects (5 females and10 males) and 80 control subjects ( 38 females and 42 males) with chronologic ages from 8 to 18 years old.

The cephalograms were imported into eDigit, version 2.1.21 software (CRIL, UOP, SanFrancisco, California, USA), where they were digitally traced using a customized digitization set that included 27 dental and skeletal landmarks and 4 fiducial markers (Fig.5). ${ }^{25}$

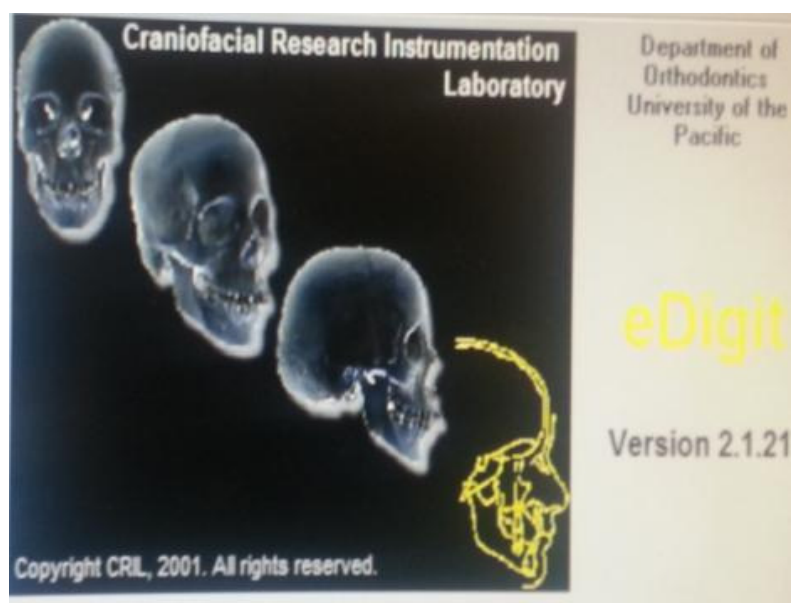

Fig. (5): eDigit software. 
Magnification of the cephalometric images was adjusted according to the appropriate enlargement factor for each growth center.

During the hard tissue landmark identification, the investigators were consistently blinded to subject and chronologic age. To increase accuracy and precision, the locations of the landmarks on each image has been measured two times and the values for each landmark have been averaged.

Cephalometric measures were derived from the customized cephalometric analysis-containing measurements from the analyses of Steiner, Jacobson, Jarabak, and McNamara. ${ }^{26-29}$

Twenty cephalometric variables were selected to assess craniofacial growth (Fig.6).

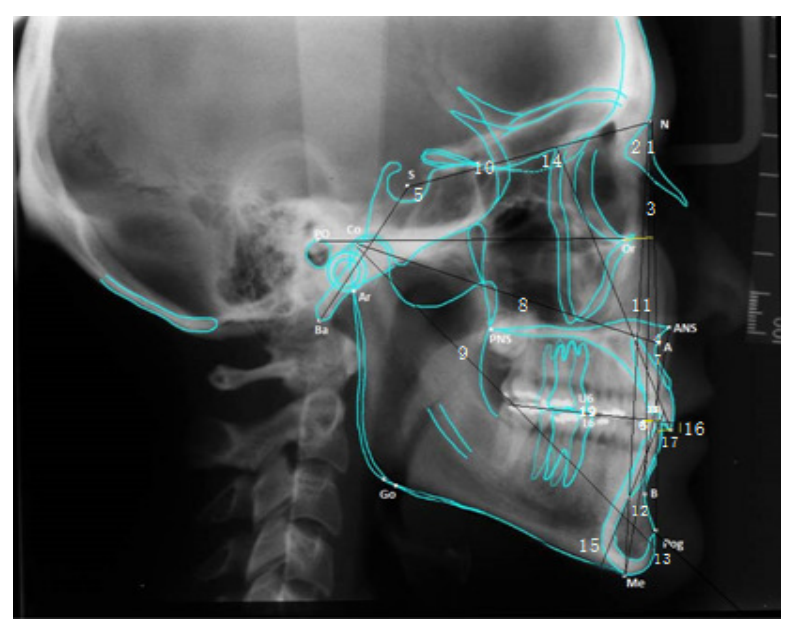

Fig. (6): Dento skeletal measurements digitally traced for cephalometric analysis.

Cervical Vertebral Staging:

The timing of cephalometric records was reassessed with respect to the pubertal growth spurt. From lateral cephalograms of good quality, the stages in cervical vertebral maturation (CVM) of Class II subjects were recorded at all subsequent observations.

On each cephalogram, the cervical vertebrae were staged using the improved version of the cervical vertebral maturation (CVM) method 
described by Baccetti. ${ }^{30}$ All readings were made on the same computer directly from the digital lateral cephalograms. (Fig.7)

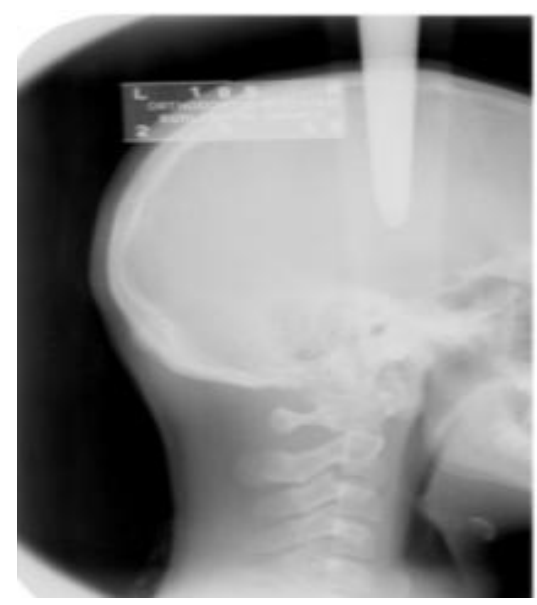

Fig. (7): Digital lateral cephalograms with only the cervical vertebrae were visible.

The CVM stage was scored twice by the same examiner, with the second scoring session three weeks later and the examiner being blind to the first scores

\section{Statistical analysis:}

Data were presented as mean and standard deviation (SD) values then explored for normality using Kolmogorov-Smirnov and ShapiroWilk tests. Data showed non-parametric (abnormal) distribution, so Kruskal-Wallis test was used for comparisons between age categories within each group.

Mann-Whitney $U$ test was used for pair-wise comparisons when Kruskal-Wallis test is significant as well as for comparisons between two groups and sexes within each group.

The significance level was set at $P \leq 0.05$. Statistical analysis was performed with $\mathrm{IBM}^{\circledR}$ SPSS ${ }^{\circledR}$ Statistics Version 20 for Windows.

(B) IBM Corporation, NY, USA.

® SPSS, Inc., an IBM Company. 


\section{RESULTS}

I. Skeletal Class II (group II) vs. Class I (group I) results; fig. (8).

Comparison between age intervals in group I and II, Sexual comparison and comparison between groups were done.

II. Skeletal Class III (Group III) Vs control (group I) results; Table (1) and fig. $(9,10)$.

i. Comparison between age groups (from T1 to T4).

ii. Comparison between males and females.

iii. Comparison between group I and group III.
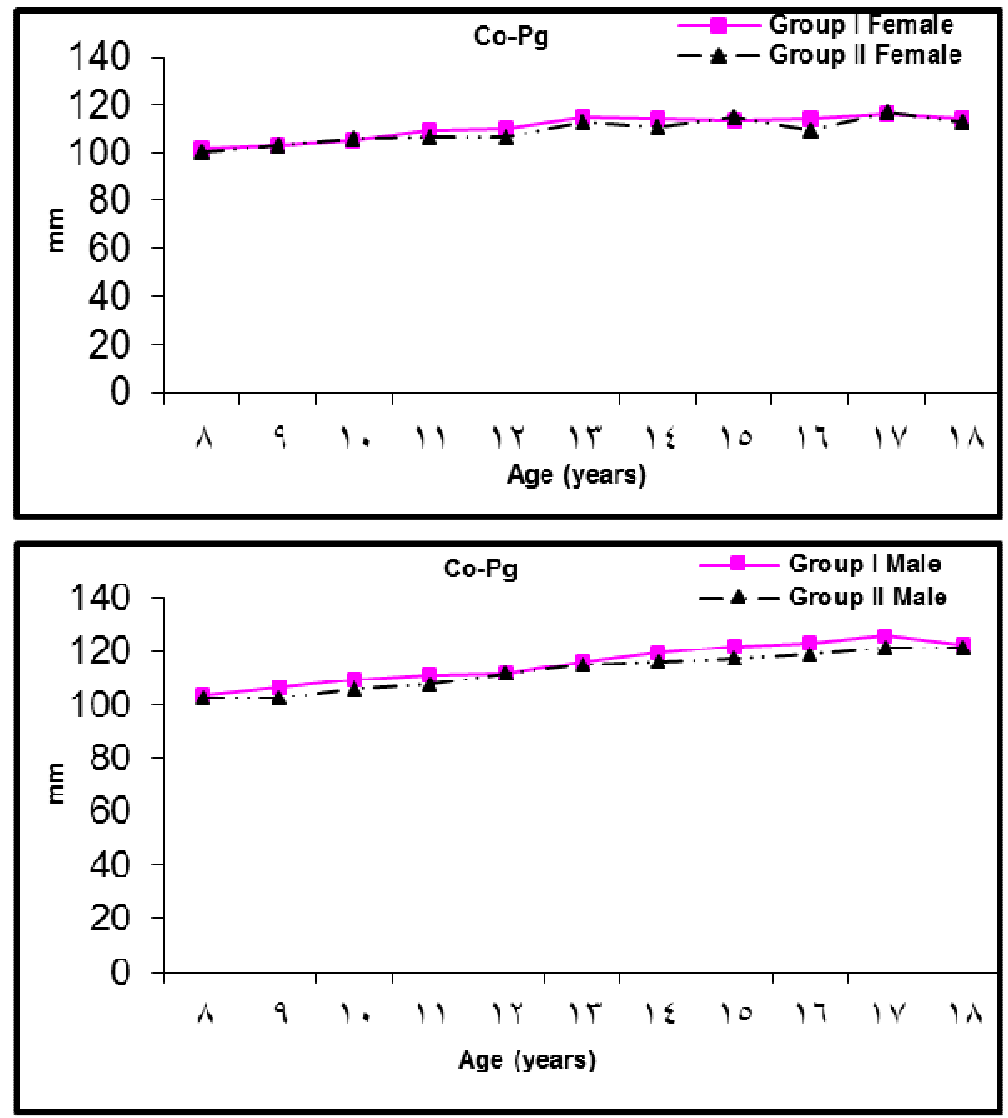

Fig. (8): Female and male group I and group II growth curves for mandibular length. 
Table (1): Descriptive statistics for maxillary base measurements and results of KruskalWallis and Mann-Whitney U tests for sex and groups comparison over age groups

\begin{tabular}{|c|c|c|c|c|c|c|c|c|c|c|c|c|c|}
\hline \multirow{3}{*}{$\begin{array}{l}\text { Maxillary } \\
\text { base }\end{array}$} & \multirow{3}{*}{ AGE } & \multicolumn{5}{|c|}{ Group I $(n=80)$} & \multicolumn{5}{|c|}{ Group III $(n=15)$} & \multirow{2}{*}{\multicolumn{2}{|c|}{$\begin{array}{l}\text { Comp. } \\
\text { I\&III }\end{array}$}} \\
\hline & & \multicolumn{2}{|c|}{$\begin{array}{c}\text { Female } \\
(n=38)\end{array}$} & \multicolumn{2}{|c|}{$\begin{array}{c}\text { Male } \\
(\mathrm{n}=42)\end{array}$} & \multirow{2}{*}{$\begin{array}{l}\text { Comp. } \\
\text { F\&M }\end{array}$} & \multicolumn{2}{|c|}{$\begin{array}{c}\text { Female } \\
(n=5)\end{array}$} & \multicolumn{2}{|c|}{$\begin{array}{c}\text { Male } \\
(\mathrm{n}=10)\end{array}$} & \multirow{2}{*}{$\begin{array}{l}\text { Comp } \\
\text { F\&M }\end{array}$} & & \\
\hline & & Mean & SD & Mean & SD & & Mean & SD & Mean & SD & & Female & Male \\
\hline \multirow{4}{*}{$\begin{array}{l}\text { Co-A } \\
(\mathrm{mm})\end{array}$} & $8-11$. & 84.32 & 6.54 & 86.81 & 6.56 & $0.00 *$ & 74.37 & 3.01 & 75.80 & 4.08 & 0.30 & $0.00^{*}$ & $0.00^{*}$ \\
\hline & 11-14. & 90.13 & 6.48 & 90.69 & 6.62 & 0.38 & 83.25 & 2.86 & 84.90 & 3.83 & 0.46 & $0.02 *$ & $0.03^{*}$ \\
\hline & 14-16 & 90.24 & 5.70 & 96.70 & 7.13 & $0.00^{*}$ & 82.90 & 1.19 & 89.17 & 3.66 & $0.00 *$ & $0.00 *$ & $0.00^{*}$ \\
\hline & $16-18$. & 92.02 & 3.31 & 96.35 & 7.70 & $0.01 *$ & 84.08 & 1.01 & 91.80 & 4.29 & $0.01 *$ & $0.00 *$ & $0.01 *$ \\
\hline \multirow{2}{*}{\begin{tabular}{|l|} 
Kruskal- \\
WallisTest
\end{tabular}} & $\mathrm{X}^{2}$ & \multicolumn{2}{|c|}{44.234} & \multicolumn{2}{|c|}{64.373} & & \multicolumn{2}{|c|}{18.446} & \multicolumn{2}{|c|}{18.446} & & & \\
\hline & P-value & \multicolumn{2}{|c|}{$<0.001^{*}$} & \multicolumn{2}{|c|}{$<0.001^{*}$} & & \multicolumn{2}{|c|}{$<0.001^{*}$} & \multicolumn{2}{|c|}{$<0.001 *$} & & & \\
\hline \multirow{4}{*}{$\begin{array}{l}\text { A-Np } \\
(\mathbf{m m})\end{array}$} & 8-11. & 2.19 & 3.31 & 2.57 & 2.71 & 0.65 & 2.58 & 2.91 & 0.97 & 2.54 & 0.28 & 0.84 & 0.17 \\
\hline & 11-14. & 3.16 & 3.53 & 3.14 & 3.71 & 0.83 & 2.85 & 2.06 & 2.38 & 5.27 & 1.00 & 0.80 & 0.95 \\
\hline & $14-16$ & 2.49 & 3.85 & 3.59 & 3.14 & 0.14 & \begin{tabular}{|l|}
7.98 \\
\end{tabular} & 4.38 & 3.10 & 5.56 & 0.24 & $0.01 *$ & 0.75 \\
\hline & 16-18. & 3.21 & 3.39 & 3.65 & 3.30 & 0.83 & 6.73 & 1.90 & 1.35 & 5.70 & 0.09 & $0.02 *$ & 0.53 \\
\hline \multirow{2}{*}{\begin{tabular}{|l} 
Kruskal- \\
WallisTest \\
\end{tabular}} & $\mathrm{X}^{2}$ & \multicolumn{2}{|c|}{3.678} & \multicolumn{2}{|c|}{4.281} & & \multicolumn{2}{|c|}{10.140} & \multicolumn{2}{|c|}{0.798} & & & \\
\hline & P-value & \multicolumn{2}{|c|}{0.298} & \multicolumn{2}{|c|}{0.233} & & \multicolumn{2}{|c|}{$0.017^{*}$} & \multicolumn{2}{|c|}{0.850} & & & \\
\hline \multirow{4}{*}{ SNA( $\left(^{\circ}\right)$} & 8-11. & 78.97 & 3.02 & 80.29 & 3.03 & 0.02 & 75.79 & 4.64 & 79.28 & 2.62 & 0.16 & $0.05^{*}$ & 0.30 \\
\hline & 11-14. & 79.72 & 3.45 & 80.79 & 2.89 & 0.05 & 75.95 & 1.63 & 82.44 & 5.01 & $0.05^{*}$ & $0.02 *$ & 0.50 \\
\hline & 14-16 & 80.43 & 3.12 & 81.52 & 3.30 & 0.07 & 74.98 & 1.91 & 82.72 & 4.86 & $0.01 *$ & $0.00^{*}$ & 0.38 \\
\hline & 16-18. & 79.36 & 3.16 & 82.97 & 3.18 & 0.00 & 74.62 & 1.82 & 80.65 & 4.34 & 0.06 & $0.00^{*}$ & 0.16 \\
\hline Kruskal- & $\mathrm{X}^{2}$ & 5.1 & & 4.6 & & & 0.7 & & 2.4 & 49 & & & \\
\hline & P-value & 0.1 & & 0.1 & & & 0.8 & & 0.4 & & & & \\
\hline
\end{tabular}

*: Significant at $P \leq 0.05$

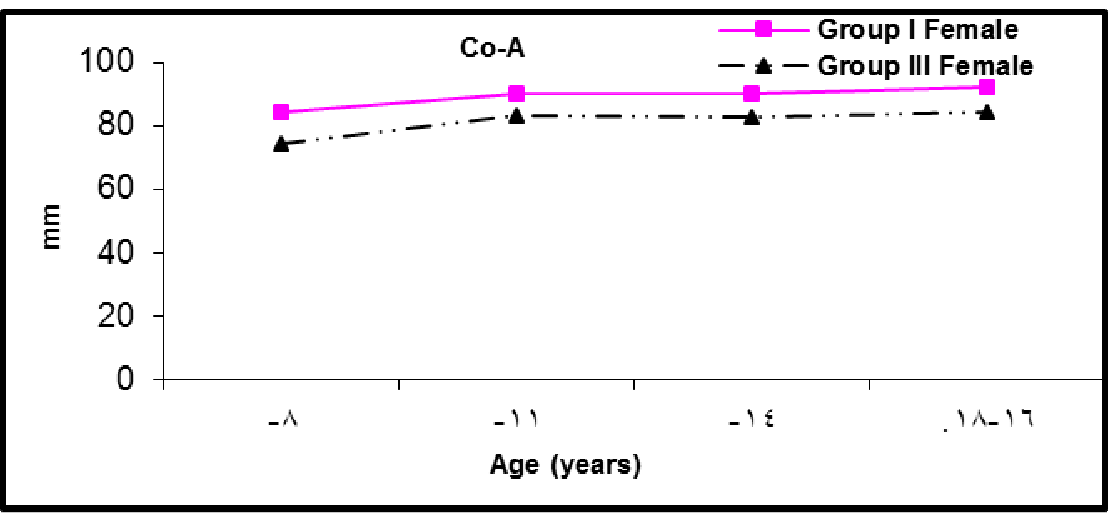


Egyptian

Orthodontic Journal

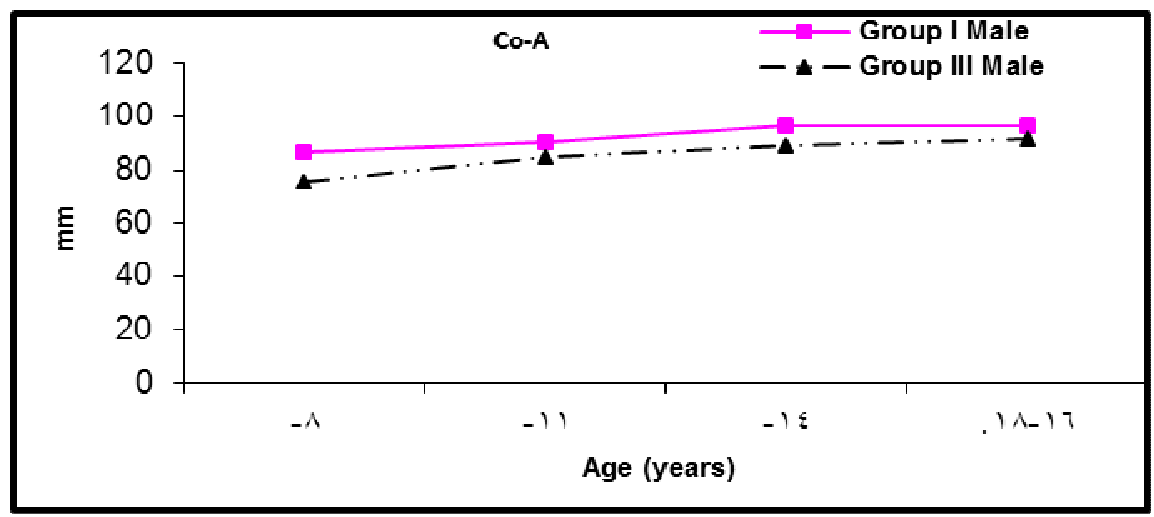

Fig. (9): Female and male group I and group III growth curves for midfacial length.
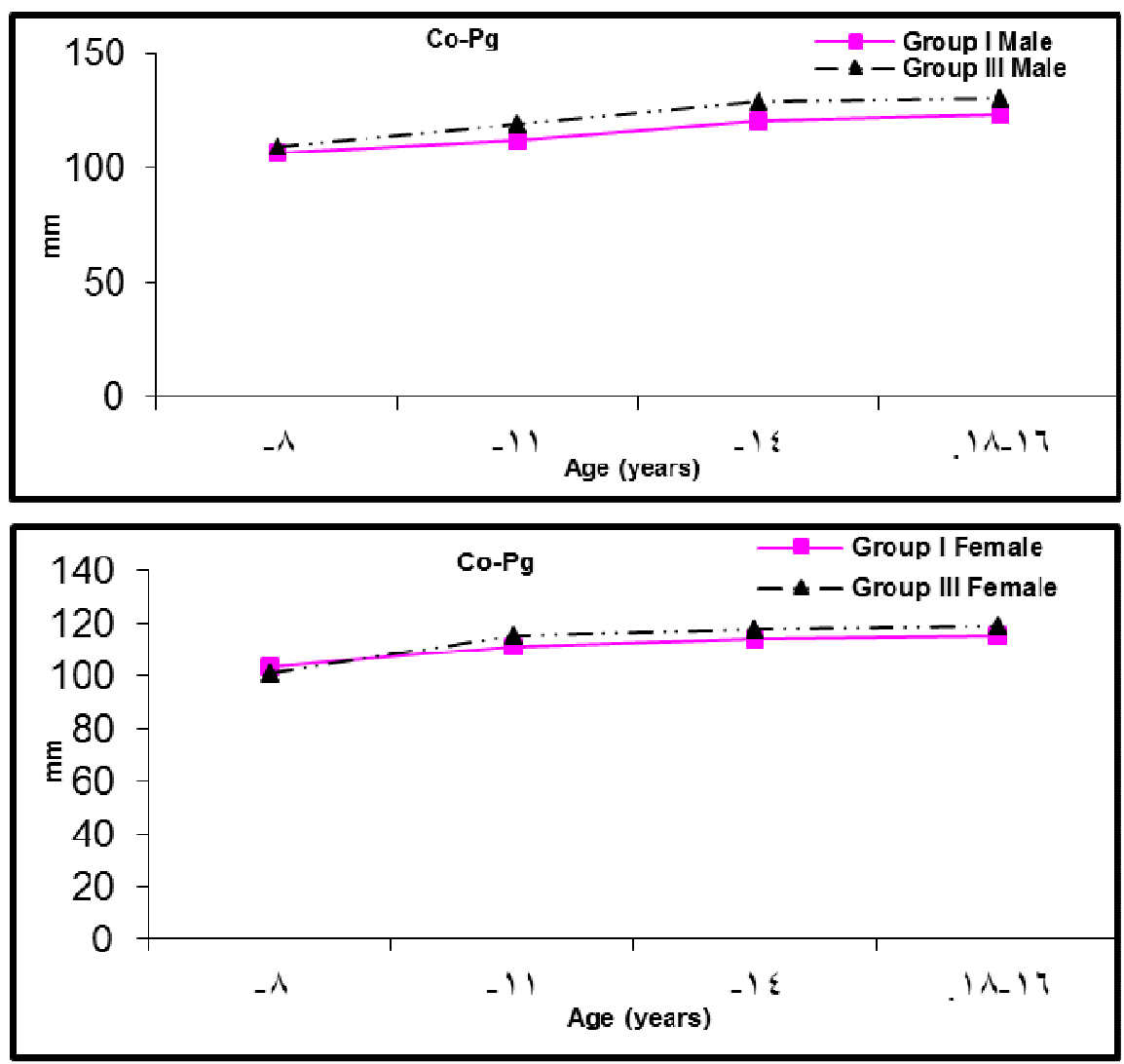

Fig. (10): Female and male group I and group III growth curves for mandibular length. 
Egyptian

Orthodontic Journal

\section{DISCUSSION}

A. Longitudinal craniofacial growth evaluation of skeletal Class II females and males compared with control group

\section{1- Cranial base measurements}

In the current study, the anterior cranial base increased in length as all subjects aged. There was no significant difference in the anterior cranial base length (S-N) between skeletal Class II and Class I in both sexes.

This finding is similar to that of two previous studies. ${ }^{31,2}$ In contrast, according to other studies ${ }^{3,10}$, (S-N) was significantly larger in the Class II division 1 females than in Class I females. The current result also disagrees with another study ${ }^{32}$ which reported that the increase in $(\mathrm{S}-\mathrm{N})$ characterized by enlarged frontal and maxillary sinus, might has been a contributing factor in development of Class II malocclusion.

There was no significant difference between Class II subjects and control group in both sexes in case of cranial base angle. In addition, the growth changes in the cranial base angle in Class II group females and males were similar to those of the controls. This result is in agreement with the finding reported by previous longitudinal study ${ }^{31}$ and cross sectional study. ${ }^{33}$ This result is in contrast to the finding of a more obtuse cranial base angle in the Class II subjects reported by other longitudinal studies $^{34,5}$ and cross sectional studies. ${ }^{35,36}$

\section{Maxillary base measurements}

There was no statistically significant difference between skeletal Class I and Class II males and females over all age intervals. The midfacial length of all subjects increased as they aged.

In both groups, no significant differences were found for the sagittal position of the maxilla. The angular relationships of the maxilla to the cranial base (SNA angle) remained stable throughout the age range.

This finding is in agreement with one cross sectional study ${ }^{37}$ and previous longitudinal studies ${ }^{31,2}$ which reported no significant difference between Class I and Class II subjects in case of cranial base dimension and 
Egyptian

Orthodontic Journal

maxillary position. In contrast, a disharmoniously anterior shift of the maxilla was the most frequent cause of a distal relationship between the 2 jaws in other studies of growth changes in Class II subjects. ${ }^{38,39,13}$

\section{2- Mandibular base measurements}

The position of the mandible relative to the cranial base as measured by the SNB angle and the distance of pogonion to nasion perpendicular was found to be significantly more retrusive and shorter in Class II subjects in both sexes as the subjects matured.

Mandibular retrognathism was observed early even at 8 years of age. These results are consistent with those of previous longitudinal studies. ${ }^{2,9,5}$

The current longitudinal study has demonstrated deficiency in the amount of total mandibular length in Class II subjects with mandibular retrusion when compared with Class I subjects at the circumpubertal period. This finding agrees with most of previous longitudinal investigations. ${ }^{1,2,9,31,40}$

The average annual increment of growth in mandibular length was approximately $1.4 \mathrm{~mm}$ for the Class II females and $2.1 \mathrm{~mm}$ for the Class II male sample. While in control group, the mandibular length increased $1.6 \mathrm{~mm}$ and $2.2 \mathrm{~mm}$ per year in females and males respectively.

\section{- Mandibular growth peak in Class II group}

Mandibular measures showed growth velocity and acceleration, indicating the adolescent growth spurt at 12 to 13 years old in females and 13 to 14 years old in males. In both sexes, the mandibular growth peak occurred at (CS3-CS4).

The analysis of the changes in the Class II subjects during the overall circumpubertal period showed significant deficiencies in mandibular length and the maxillo mandibular differential $(-2.7 \mathrm{~mm}$ in males and $-1.5 \mathrm{~mm}$ in females).

The current results agree with previous study ${ }^{5}$ that reported a significant deficiency in mandibular growth of $2.9 \mathrm{~mm}$ in the Class II subjects from CS1 through CS6. These results also agree with another study $^{34}$ that reported an average deficiency in mandibular growth in Class II subjects of about $2.5 \mathrm{~mm}$ from 5 through 15 of age. 
Egyptian

Orthodontic Journal

Another study ${ }^{2}$ reported also a significant smaller increase in total mandibular length in Class II subjects from 7 through 14 years; however, the difference inmandibular growth between the Class II and Class I subjects was much larger $(9.6 \mathrm{~mm})$ than reported in the current study and the previously mentioned studies. 5,34

In contrast, other two longitudinal studies ${ }^{3,7}$ showed no significant difference in mandibular growth between Class II and Class I subjects from the deciduous through the permanent dentitions.

\section{4- Jaw relationship}

In the current study, the convexity showed a statistically significant increase in skeletal Class II subjects except at ages 9, 17 and 18 in males and from 14 to 17 years in females where there was no statistically significant difference between groups. This finding indicates that the facial profile in skeletal Class II is more convex than in skeletal Class I subjects which come in agreement with other studies. ${ }^{3,5,72}$

\section{5- Vertical skeletal measurements}

In the present study, no significant difference was noticed in the lower anterior facial height (LAFH) between skeletal Class I and Class II in both sexes.

This finding comes in agreement with previous studies ${ }^{5,32}$ in which no significant differences between the 2 study groups were found with regard to vertical growth pattern. On the other hand, this result disagrees with other previous studies reporting increased vertical skeletal relationships in patients with Class II malocclusion ${ }^{2,}{ }^{41}$.This may be attributed to the variations in the ethnic groups or the methods used.

\section{6- Dental measurements}

No significant differences were seen in the interincisal angle between the 2 groups except Class II females from 8 to 11age intervals showed a statistically significant lower mean interincisal angle than Class I group. The compensatory growth between the upper and lower dental arches can explain this finding. 
Egyptian

Orthodontic Journal

The angulations of the upper incisor in relation to SN plane (U1-SN) showed no statistically significant difference between the two groups in both sexes at all age points. This finding is similar to another longitudinal study. ${ }^{5}$

The inclination of the lower incisors to mandibular plan (IMPA) showed no significant difference between groups except at age points of 8 and 16 years in females and at 13 years in males where lower incisors became more proclined in Class II group. These findings more or less agree with one longitudinal study ${ }^{72}$ but disagree with other studies. ${ }^{12,32}$

\section{7- Comparison between skeletal Class II males and females sample}

Most of the angular and linear measurements used in this study showed no significant difference between Class II males and females. The current findings are in agreement with the literature which reported that gender exerts little or no effect on skeletal and dental components in Class II malocclusions. ${ }^{42,43}$ Although most of the linear measurements were higher in skeletal Class II males, this difference was not statistically significant.

B. Longitudinal craniofacial growth evaluation of skeletal Class III females and males compared with control group

1- Cranial base measurements

Class III subjects exhibited a statistically significant shorter anterior cranial base than control group. This result agrees with several previous studies. ${ }^{44-46}$ In contrast, another study found a significant increase in anterior cranial base length, measured as nasion to the foramen caecum, in Class III subjects when compared to controls. ${ }^{47}$ On the contrary, a previous longitudinal study ${ }^{48}$ reported similarity in anterior cranial base length between Class III and Class I subjects.

There was no statistically significant difference in cranial base angle between Class III subjects and control in both sexes at all age groups. This finding agrees with previous longitudinal study ${ }^{48}$. However, this finding disagrees with previous studies that reported a more acute cranial base angle in Class III subjects. ${ }^{17,45,49}$ 
Egyptian

Orthodontic Journal

2. Maxillary base measurements

The midfacial length of all subjects increased as they aged. Class III females as well as males showed a significantly smaller midfacial length in comparison to controls from ages 8 to 18 years. This result is in agreement with previous investigations ${ }^{44,50}$ that reported a significantly smaller midface length (Co-A) in Class III subjects from ages 8 to 15 years.

However, the current finding disagrees with two previous longitudinal investigations ${ }^{22,48}$ that reported no significant difference in midface length between the two groups. The variation in finding may be attributed to the lack of control group in the first study. Whereas the primary limitation of the second study was the lack of multiple time points per subject.

In the current study, no difference was found between Class III males and control groups for the sagittal position of the maxilla. While a significantly smaller SNA values was found in Class III females relative to controls. However, some previous studies reported a non-significant difference of SNA between Classes in both sexes. ${ }^{22,48-51}$

\section{3-Mandibular base measurements}

Relative to control, Class III subjects have shown smaller ANB differences and greater SNB angles. These findings are consistent with those of cross-sectional ${ }^{44,45,49}$ and longitudinal researches. ${ }^{22,48}$

The results of this study revealed greater total mandibular length in Class III group than control group in both sexes. This finding is in agreement with several authors reported either greater total mandibular length or greater mandibular body length as a significant component of the Class III relationship in adolescents and children. ${ }^{22,48-50}$

The average annual increment of growth in mandibular length in the current study was approximately $1.7 \mathrm{~mm}$ for the female sample and $3.2 \mathrm{~mm}$ for the male sample. The current finding concerning Class III males agrees with the estimated increments of growth from untreated white Class III groups reported in previous studies ${ }^{(18,22,48,51-54)}$. 
Egyptian

Orthodontic Journal

In the present study, the total accumulated mandibular lengthening values in the Class III samples between 8 and 16 of age were approximately $17 \mathrm{~mm}$ for females and $23 \mathrm{~mm}$ for males; these closely agree with previous longitudinal ${ }^{53}$ and cross-sectional ${ }^{55,56}$ data on male and female subjects pooled (about 19.5 and $20.3 \mathrm{~mm}$, respectively).

- Mandibular growth peak in Class III group

In the present investigation, there was a significant increase in mandibular length in Class III subjects from 11 years in females and 14 years in males through 18 years of age group. This finding is in agreement with previous cross-sectional study $^{49}$ in which the mandibular growth peak in Class III subjects occurred on average 1 year later than control (at ages 13-14 in males and 11-12 in females).The increases in mandibular length during the pubertal peak were larger and lasted longer in Class III subjects even during the more mature age interval (15 to 16 years old).

The current finding disagrees with previous longitudinal study ${ }^{48}$ in which the growth in Class III malocclusion followed the established pattern of normal craniofacial growth more adequately than in cross-sectional studies. However, the limitation of this study was the lack of controls.

The current results have demonstrated an extended duration of the mandibular growth spurt in boys with Class III malocclusions over second and third age groups (to 16 years).This closely agrees with previous investigations ${ }^{48,56}$ which reported that the amount of annual increase in mandibular length in Class III boys was consistently over $3 \mathrm{~mm}$ from age 12 to 15 years.

In the current study, the amount of residual mandibular growth after the pubertal growth spurt should be emphasized in Class III subjects, after second age group (11-14yrs) in girls and after third group (14-16yrs) in boys and until last age group (16 to 18yrs) in both groups.

This finding agrees with previous large cross-sectional study ${ }^{49}$ that demonstrated significant changes in Class III total mandibular length of about $8 \mathrm{~mm}$ in boys and $5.5 \mathrm{~mm}$ in girls which continued after the peak of growth until young adulthood (18 years on average). 
Egyptian

Orthodontic Journal

4- Jaw relationship

Results have shown a statistically significant decrease in the ANB angle, Wits appraisal and molar relationship. All indicate worsening of the Class III relationship over time mainly due to continuous mandibular growth in a forward direction relative to the maxilla.

The decreases in the WITS measures have been previously reported for Class III subjects followed longitudinally. ${ }^{22,48,52}$

\section{5- Vertical skeletal measurements}

The lower anterior facial height (LAFH) was significantly larger in Class III group resulting in a significantly larger total anterior facial height (TAFH).This result can be explained by mandibular growth in a forwarddownward direction in Class III subjects. This finding is in consistence with previous studies. $^{22,48}$

In Class III, the average annual increments of growth in lower anterior face height for the female and male samples were 1.1 and $1.2 \mathrm{~mm}$, respectively.

\section{6- Dentoalveolar measures}

The position of the maxillary permanent incisor (U1-SN ${ }^{\circ}$ ) was relatively constant in subjects with Class III and normal occlusions. This finding disagrees with previous longitudinal study ${ }^{48}$ which reported that the permanent maxillary incisor tended to increase in both proclination and protrusion relative to the maxillary base in both sexes as the subjects aged.

The mandibular permanent incisors relative to the lower border of the mandible (IMPA) showed lower values in Class III sample than in control group over time in both sexes. This finding is in contrast to previous longitudinal study ${ }^{48}$ which reported that angular measurement IMPA in the female sample had greater negative changes than in the males. For the interincisal angle $\left(\mathrm{U} 1 / \mathrm{L} 1^{\circ}\right)$, no significant differences were found between Class III and control groups. 
7- Comparison between males and females of Class III group

Sex differences were small during childhood and became pronounced during adolescence which mainly consisted of differences between linear measurements. This finding agrees with what was confirmed recently by other studies. ${ }^{45,48,56,57}$

\section{CONCLUSION}

1. Most dentofacial measures in Class II subjects were similar to control group, with the exception of significant mandibular retrusion, higher value of wits appraisal and ANB angle, distal molar relationship, greater skeletal convexity and deficiency in mandibular length.

2. The skeletal and dental components of Class II and Class III malocclusion were evident early and didn't tend to self-correct but tended to worsen with growth.

3. In Class II group, the adolescent growth spurt in mandibular length occurred at 12 to 13 years of age in females and 13 to 14 years of age in males. In both sexes, the mandibular growth peak occurred between cervical vertebral stages three and four (CS3-CS4).

4. Most of the angular and linear measurements showed no significant sex difference in Class II group. In contrast, presence of a sexual dimorphism was evident in Class III group.

5. Relative to controls, Class III subjects displayed smaller anterior cranial base length, similar cranial base angle, shorter maxilla, more prominent mandible, and increases in lower anterior facial height. The maxilla, while being short, is in a similar position in Class III males but retrusive in Class III females.

6. The peak of mandibular growth in Class III group showed a later onset, longer duration, and larger amount than controls.

7. The amount of residual mandibular growth after the pubertal growth spurt (over 16yrs of age) should be emphasized in Class III subjects. 
Egyptian

Orthodontic Journal

\section{REFERENCES}

1- Carter NE. Dentofacial changes in untreated Class II Division 1 subjects. Br J Orthod.1987; 14:225-34.

2- Ngan PW, Byczek E, Scheick J. Longitudinal evaluation of growth changes in Class II division 1 subjects. Semin Orthod.1997; 3:222-31.

3- Bishara SE, Jakobsen JR, Vorhies B, Bayati P. Changes in dentofacial structures in untreated Class II division 1 and normal subjects: a longitudinal study. Angle Orthod.1997; 67:55-66.

4- Ishii N, Deguchi T, Hunt NP. Craniofacial morphology of Japanese girls with Class II division 1 malocclusion.J Orthod.2001; 28:211-5.

5- Stahl F, Baccetti T, Franchi L, McNamara JA Jr.Longitudinal growth changes in untreated subjects with Class II Division 1 malocclusion.Am J Orthod Dentofac Orthop. 2008;134:125-37.

6- Baccetti T,Stahl F, McNamara JA Jr. Dentofacial growth changes in subjects with untreated Class II malocclusion from late puberty through young adulthood.Am J Orthod Dentofac Orthop.2009; 135:148- 54 .

7- Bishara SE. Mandibular changes in persons with untreated and treated Class II division 1 malocclusion.Am J Orthod Dentofac Orthop. 1998; 113: 661-73.

8- You ZH, Fishman LS, Rosenblum RE, Subtelny JD. Dentoalveolar changes related to mandibular forward growth in untreated Class II persons. Am J Orthod Dentofac Orthop.2001; 120: 598-607.

9- Lux CJ , Raeth O, Burden D, Conradt C, Komposch G. Sagittal and Vertical Growth of the Jaws in Class II, Division 1 and Class II, Division 2 Malocclusions during Pre pubertal and Pubertal Development.J Orofac Orthop. 2004;65:290-311

10- Hitchcock HP. A cephalometric description of Class II, Division 1 malocclusion.Am J Orthod.1973; 63:414-23.

11- El-Mangoury NH. Skeletal components of Angle Class II malocclusion. Egy Orthod.1990; 4:57-67. 
Egyptian

Orthodontic Journal

12- Chung $\mathrm{CH}$, Wong WW. Craniofacial growth in untreated skeletal Class II subjects: A longitudinal study. Am J Orthod Dentofac Orthop.2002; 122:619-26.

13- VásquezM J, Baccetti T, Franchi L, McNamara JA Jr. Dentofacial features of Class II malocclusion associated with maxillary skeletal protrusion: A longitudinal study at the circumpubertal growth period.Am J Orthod Dentofac Orthop. 2009; 135:568.e1-7.

14- Ishii N, Deguchi T, Hunt NP.Craniofacial differences between Japanese and British Caucasian females with a skeletal Class III malocclusion. Eur J Orthod.2002; 24: 493-9.

15- Mouakeh M. Cephalometric evaluation of craniofacial pattern of Syrian children with Class III malocclusion. Am J Orthod Dentofac Orthop.2001; 119:640-9.

16- Connor AM, Moshiri F. Orthognathic surgery norms for American black patients. Am J Orthod.1985; 87: 119- 34.

17- Alkhamrah B, Terada K, Yamaki M, Ali IM, Hanada K. Ethnicity and skeletal Class III morphology: a pubertal growth analysis using thin-plate spline analysis.Int J Adult Orthod Orthognath Surg. 2001; 16: $243-54$.

18- Baccetti T, McGill JS, Franchi L, McNamara JA Jr, Tollaro I. Skeletal effects of early treatment of Class III malocclusion with maxillary expansion and face-mask therapy. Am J Orthod Dentofac Orthop.1998; 113:333-43.

19- Deguchi T, Kuroda T, Minoshima Y, Graber TM. Craniofacial features of patients with Class III abnormalities: growth related changes and effects of short-term and long-term chincup therapy. Am J Orthod Dentofac Orthop.2002; 121:84-92.

20- Bandai-Sakamoto E, Sugawara J, Umemori M, Mitani H. Craniofacial growth of mandibular prognathism in Japanese girls during pubertal growth period: longitudinal study from 9 to 14 of age. Orthod Waves.2000; 59:77-89. 
21- Miyajima K, McNamara JA Jr, Kimura T, Murata S, lizuka T. An estimation of craniofacial growth in the untreated Class III female with anterior crossbite.Am J Orthod Dentofac Orthop.1997; 112:425-34.

22- Wolfe SM, Araujo E, Behrents RG, Buschang PH. Craniofacial growth of Class III subjects six to sixteen years of age. Angle Orthod.2011; 81:211-6.

23- Moore RN, Moyer BA, DuBois LM. Skeletal maturation and craniofacial growth. Am J Orthod Dentofac Orthop. 1990;98:33-40.

24- Baumrind S, Curry S. The AAOF Craniofacial Growth Legacy Collection: A powerful new tool for Orthodontic Teaching and Research.Univ. of Michigan Craniofacial Growth Series.2011;48:297-316.

25- Baumrind S, Miller DM. Computer-Aided Head Film Analysis: The University of California, San Francisco Method.Am. J. Orthod.1980; 78:41-65.

26- Steiner C. Cephalometrics for you and me. Am J Orthod.1953; 39:729-55.

27- Jacobson A. The "Wits" appraisal of jaw disharmony. Am J Orthod. $1975 ; 67: 125-138$.

28- Jarabak J, Fizzel J. Technique and Treatment with Light Wire Edgewise Appliances. St Louis, Mo: Mosby; 1972.

29- McNamara JA. A method of cephalometric evaluation. Am J Orthod. 1984;86: 449-69.

30- Baccetti T, Franchi L, McNamara JA Jr. The cervical vertebral maturation (CVM) method for the assessment of optimal treatment timing in dentofacial orthopedics. Semin Orthod.2005; 11:119-29.

31- Buschang PH, Tanguay R, Turkewicz J. A polynomial approach to craniofacial growth: description and comparison of adolescent males with normal occlusion and those with untreated Class II malocclusion. Am J Orthod Dentofac Orthop.1986; 90:437-42. 
32- Rothstein T, Yoon-Tarlie C. Dental and facial skeletal characteristics and growth of males and females with Class II, Division 1 malocclusion between the ages of 10 and 14 (revisited) - Part I: characteristics of size, form, and position.Am J Orthod Dentofac Orthop. 2000; 117:320-32

33- Rothstein T, Phan XL. Dental and facial skeletal characteristics and growth of females and males with Class II Division 1 malocclusion between the ages of 10 and 14 (revisited). Part II. Anteroposterior and vertical circumpubertal growth. Am J Orthod Dentofac Orthop.2001;120:542-55.

34- Kerr WJ, Hirst D. Craniofacial characteristics of subjects with normal and postnormal occlusions - a longitudinal study.Am J Orthod Dentofac Orthop.1987; 92:207-12.

35- Baccetti T, Antonini A, Franchi L, Tonti M, Tollaro I. Glenoid fossa position in different facial types: A cephalometric study. $\mathrm{Br} \mathrm{J}$ Orthod.1997;24:55-9.

36- Droel R, Isaacson RJ. Some relationships between the glenoid fossa position and various skeletal discrepancies. Am J Orthod.1972; 61:64-78.

37- Pereira JC, Lederman HM, Yamashita HK, Pereira DQ, Aidar LA. Comparative cephalometric study of dentofacial patterns of individuals with normal occlusion and Angle malocclusions. Dent Press J Orthod.2011; 16:62-73.

38- Gesch D.A longitudinal study on growth in untreated children with Angle Class II, Division 1 malocclusion. J Orofac Orthop.2000; 61:20-33.

39- Antonini A, Marinelli A, Baroni G, Franchi L, Defraia E.Class II malocclusion with maxillary protrusion from the deciduous through the mixed dentition: a longitudinal study. Angle Orthod. 2005; 75:980-6.

40- Anderson DL, Popovich F. Lower cranial height vs. craniofacial dimensions in Angle Class II malocclusion. Angle Orthod.1983; 53:253-60. 
Egyptian

Orthodontic Journal

41- Riesmeijer A M, Prahl-Andersen B, Mascarenhas AK, Joo B H, Vig KW. A comparison of craniofacial Class I and Class II growth patterns. Am J Orthod Dentofac Orthop.2004; 125: 463-71.

42- Freirss MR,Santos AC,Freitas MS,Janson G, Freita DS, Henriques FC.Cephalometric characterizationof skeletalClass II, division 1 malocclusionin whiteBrazilian subjects.J Appl Oral Sci. 2005; 13: 198-203.

43- Jamison JE, Bishara SE, Peterson IC, Dekock WH, Kremanak CR. Longitudinal changes in the maxilla and the maxillary-mandibular relationship between 8and 17of age. Am. J. Orthod.1982; 82: 217-30.

44- Tollaro I, Baccetti T, Bassarelli V, Franchi L.Class III malocclusion in the deciduous dentition: a morphological and correlation study.Eur J Orthod.1994; 16:401-8.

45- Battagel JM.The aetiological factors in Class III malocclusion. Eur J Orthod.1993; 15, 347-70.

46- Jacobson A, Evans WG, Preston CB, Sadowsky PL. Mandibular prognathism. Am J Orthod.1974;66:140-71.

47- Proff P, Will F, Bokan I, Fanghanel J, Gedrange T. Cranial base features in skeletal Class III patients.Angle Orthod. 2008;78:433-9.

48- Alexander A, McNamara JA Jr, Franchi L, Baccetti T. Semi longitudinal cephalometric study of craniofacial growth in untreated Class III malocclusion. AmJ Orthod Dentofac Orthop. 2009; 135:700.e1-14.

49- Reyes BC, Baccetti T, McNamara JA. An estimate of craniofacial growth in Class III malocclusion.Angle Orthod.2006; 76:577-84.

50- Guyer EC, Ellis E, McNamara JA Jr, Behrents RG. Components of Class III malocclusion in juveniles and adolescents.Angle Orthod. 1986; 56:7-30.

51- Macdonald KE, Kapust AJ, Turley PK. Cephalometric changes after correction of Class III malocclusion with maxillary expansion/facemask therapy. Am J Orthod Dentofac Orthop.1999;116:13-24. 
52- Baccetti T, Franchi L, McNamara JA Jr. Growth in the untreated Class III subject. Semin Orthod.2007; 13:130-42.

53- Baccetti T, Franchi L, McNamara JA Jr.Treatment and posttreatment craniofacial changes after rapid maxillary expansion and facemask therapy.Am J Orthod Dentofac Orthop. 2000;118: 404-13.

54- Westwood PV, McNamara JA Jr, Baccetti T, Franchi L, Sarver DM. Long-term effects of Class III treatment with RME and facial mask therapy followed by fixed appliances. Am J Orthod Dentofac Orthop.2003; 123:306-20.

55- Baccetti T, Reyes BC, McNamara JA Jr.Craniofacial changes in Class III malocclusion as related to skeletal and dental maturation.Am $\mathrm{J}$ Orthod Dentofac Orthop. 2007;132:171.e 1-12.

56- Baccetti T, Reyes BC, McNamara JA. Gender differences in Class III malocclusion.Angle Orthod.2005; 75:510-20.

57- Dibbets JM. Morphological associations between the Angle's Classes. Eur J Orthod.1996; 18: 111-8. 